\title{
Designing and Creating Digital Interactive Content Framework: Description and Evaluation of the Almekhlafi Digital Interactive Content Model
}

\author{
Abdurrahman Ghaleb Almekhlafi* \\ Department of Curriculum and Instruction, College of Education, United Arab Emirates University, Al-Ain, Abu Dhabi, United Arab Emirates \\ *Corresponding Author: almekhlafi@uaeu.ac.ae
}

\section{ABSTRACT}

The design and creation of digital interactive content for teaching and learning are gaining increasing importance. As this technology advances, the need to cope with everyday demands necessitates teachers and content developers to accommodate their students in this aspect. Interactive digital content provides opportunities for students to study anywhere and anytime, with classmates or independently, and within conventional or blended teaching and learning environments. The Almekhlafi Digital Interactive Content (ADIC) model is a systematic guide that could be used to produce interactive digital content on any subject. This model can serve as a framework for developing such content. The model consists of four major phases: Planning, designing, production, and evaluation. Each of these phases consists of a number of steps. The model was content-validated and tested for its reliability in real contexts. The model was piloted with 28 university faculty members and implemented with 81 university students. The results support the implementation of the model for designing and creating interactive digital content. The paper recommends that K-12 schools and higher education institutions should train students, teachers, and university faculty members to use the model effectively for producing sound, worthwhile, and interactive digital educational content.

KEY WORDS: instructional design; interactive digital content; Almekhlafi Digital Interactive Content model

\section{INTRODUCTION}

I nstructional developers require instructional design models to produce well-structured content. Thus far, numerous such models have been developed. The most widely used model is that proposed by Dick and Carey (1996), and the successive approximation model (SAM) is the most recent. Other well-known models include ADDIE, ARCS, ASSURE, four-component instructional design (4C-ID), and backward design models. All of these models have been used for different contexts and purposes to develop instructional content. These models have been extensively studied, implemented, evaluated, analyzed, and compared against each other. Many researchers have authored books and published research articles investigating, analyzing, implementing, and explaining these models in detail, including Dick and Reiser (1989); Dick (1996); Dick and Carey (1996); Dick et al. (2001); Chang (2006); Dick et al. (2015); and Rothwell et al. (2015).

Regarding the Dick-and-Carey instructional design model (Figure 1), its first version was developed in 1968 at Florida State University. Dick (1996) indicated that four editions of the model were released $(1978,1985,1990$, and 1996) under the title "The Systematic Design of Instruction." According to Chang (2006), the Dick-and-Carey model uses the system approach for designing effective instructions.
Another well-documented model is the ADDIE model (Figure 2), an instructional system design framework that has been used by many designers and course developers. This model comprises five phases that lead to the building of training and performance-support tools. It illustrates the conceptual framework of the instructional design (Branch, 2009; Morrison, 2010; Gustafson and Branch, 2002). Branch (2009) provided an overview of the ADDIE model by stating that the primary rationale for the study was to respond to the need for an instruction design primer that addresses the current proliferation of complex educational development models, particularly nonconventional approaches to learning, multimedia development, and online learning environments.

Similarly, the ARCS model (Figure 3) was developed by John Keller and introduced to the public in 1979. The main concept of the model is to break the learner motivation into four different components - attention, relevance, confidence, and satisfaction - that constitute the model. According to the developer, the model provides strategies for instructors to incorporate into their courses, for encouraging learner motivation. The model has been widely applied and has become the focus of research into learner motivation (Francom and Reeves, 2010).

The ASSURE model is another instructional design model for developing technology-enhanced lessons (Heinich et al., 1999). Each letter in the acronym ASSURE represents the steps that 


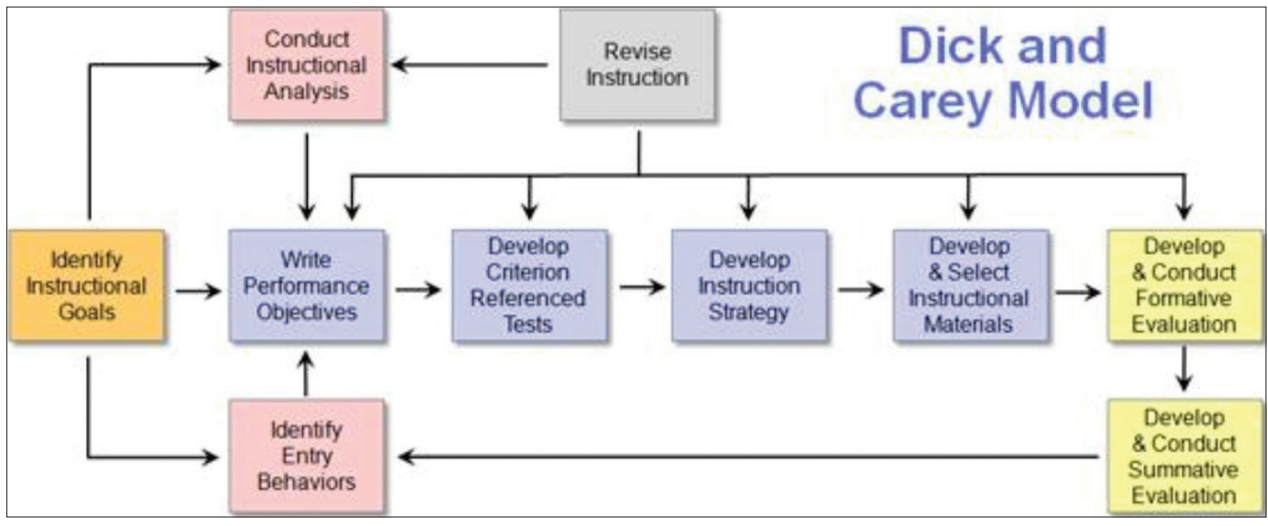

Figure 1: Representation of the Dick-and-Carey model

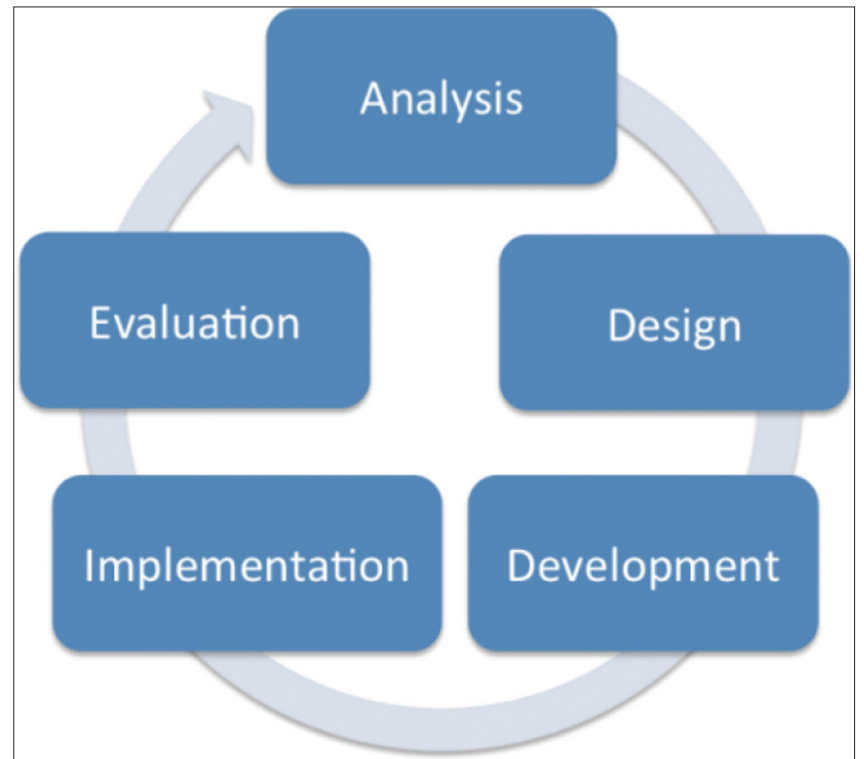

Figure 2: Representation of the ADDIE model

the model constitutes, as shown in Figure 4. The authors argued that when implementing the ASSURE model, teachers would have a curriculum to teach in the classroom, with specific objectives that will become the focus of individual lessons.

Following the same path, the 4C-ID model, represented in Figure 5 and developed by Van Merriënboer et al. (2002), focuses on four components: (1) Learning tasks, (2) supportive information, (3) procedural information, and (4) part-task practice. These four tasks are ordered according to their difficulty level. According to Van Merriënboer et al. (2002), the model addresses at least three deficits in the previous instructional design models. The model (1) focuses on the integration and coordinated performance of task-specific constituent skills rather than knowledge types, (2) makes a critical distinction between supportive information and justin-time information, and (3) recommends the use of a mixture of part- or whole-task practice, which is not provided by conventional models (Van Merriënboer, 1997; Merrill, 2002).

The backward design model (Figure 6) is another instructional model that has been used by designers (Wiggins and McTighe,

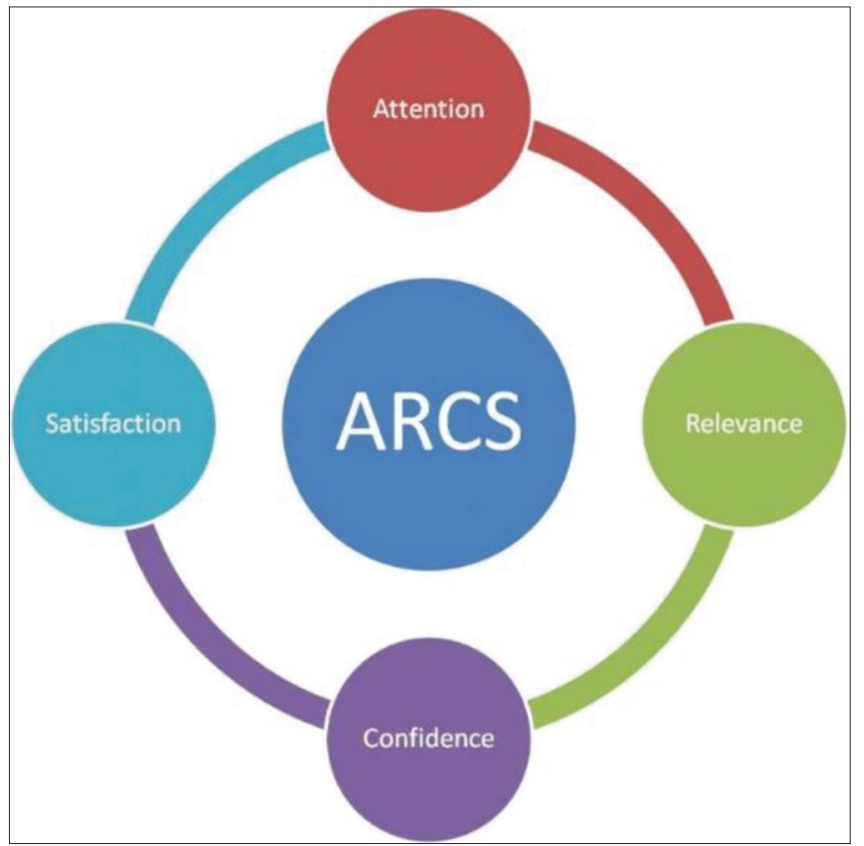

Figure 3: Representation of the ARCS model

1998, 2005). The steps and application of this model have been extensively explained in two editions of the book Understanding by Design, published in 1998 and 2005.

Many other researchers have focused on the use of the Kemp Design Model (Figure 7), such as Akbulut (2007), Morrison (2010), and Kurt (2016). This model provides an instructional design of a non-linear structure and adopts a circular structure rather than a linear structure (Akbulut, 2007).

Finally, the SAM is the most recent model that has gained the attention of designers and curriculum developers. This model, as represented in Figure 8, was created by Allen Interactions. The model provides designers with an instructional design approach consisting of repeated small steps or iterations intended to address some of the most common instructional design components (Crowe, 2019).

Although these models have focused on instructional design with respect to ubiquitous learning contexts and environments, 
none of them have focused on designing and creating interactive digital content. Thus, the Almekhlafi Digital Interactive Content (ADIC) model is proposed; the model addresses this gap and provides guidelines for designers and curriculum developers to design interactive digital content

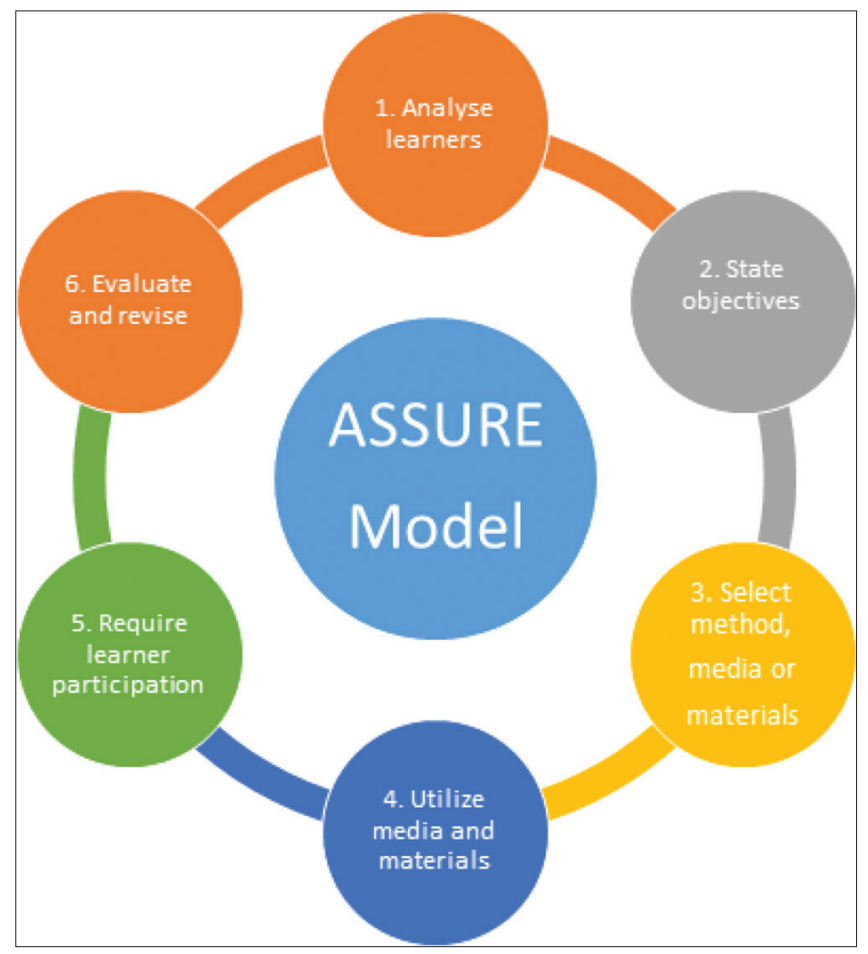

Figure 4: Representation of the ASSURE model for effective learning and teaching. The proposed model has been validated and implemented in a research-based context

\section{RESEARCH QUESTIONS}

Aimed at investigating the utility of the proposed ADIC model, the following three questions were addressed:

1. How do students perceive the utility of the ADIC model for designing and developing interactive digital content?

2. To what extent do participants implement the ADIC model for creating digital interactive content?

3. To what extent do participants intend to use or recommend the ADIC model to colleagues or others for the design and development of digital content materials?

\section{ADIC MODEL DESCRIPTION}

\section{Definition}

ADIC is a guide for designing and developing digital interactive content for training, teaching, and learning purposes. Instructional designers, curriculum developers, teachers, and students can use the model to design and create interactive digital content for different purposes, including content for K-12 schools, universities, and training institutions.

\section{Model Uses}

The model is generic and sufficiently flexible to be adapted for designing and developing a variety of digital interactive content such as training modules, interactive lectures, computerized curriculum, independent learning/tutorials, interactive multimedia, flipped classroom, blended learning materials,

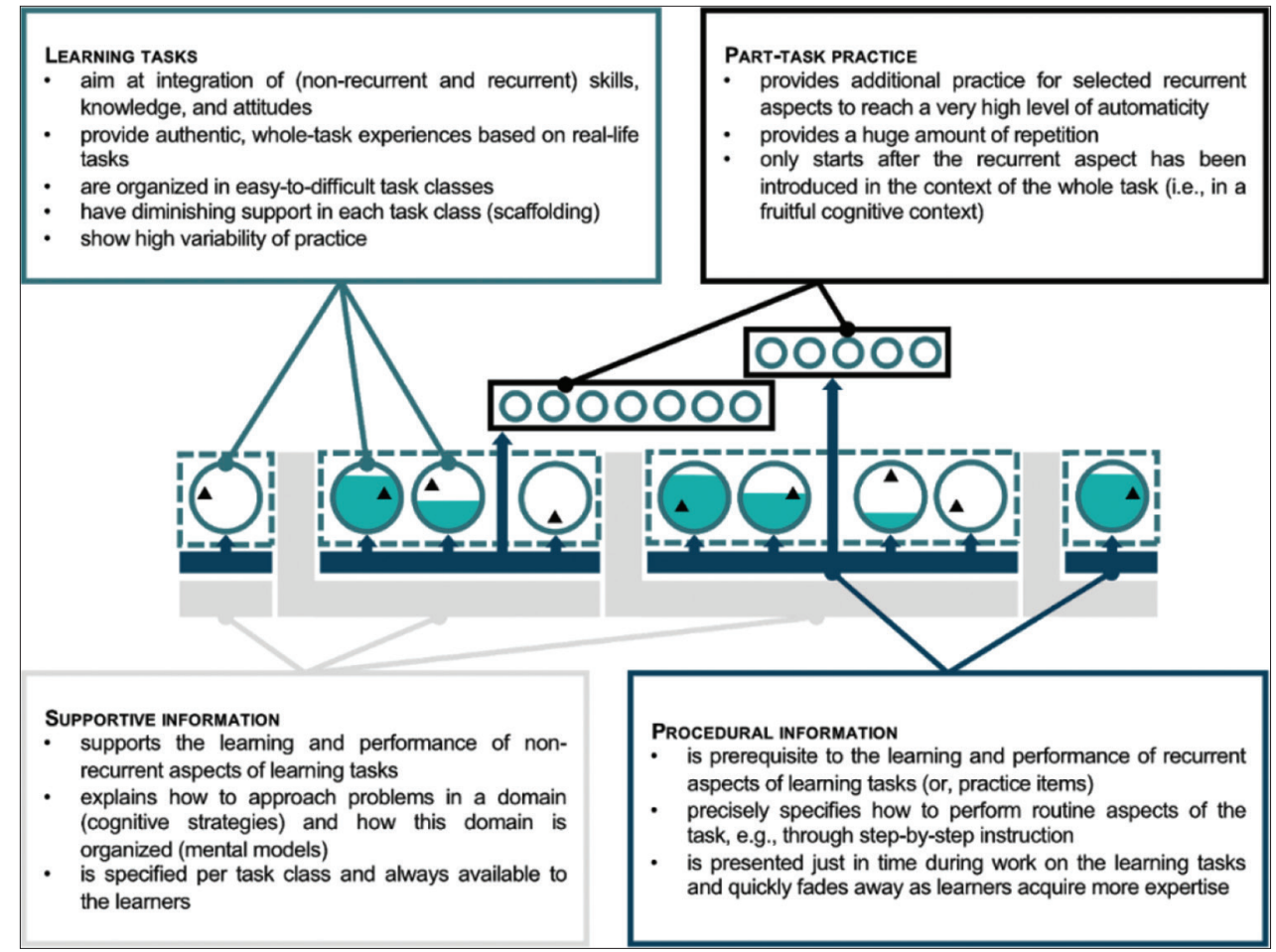

Figure 5: Representation of the four-component instructional design model. Image source: https://www.4cid.org/about-4cid 
educational websites, open educational resources, eLearning courses, and massive open online courses. Depending on the type of project to be developed, some steps might be excluded and skipped without jeopardizing the product quality.

\section{MODEL PHASES AND STEPS}

The proposed model consists of four main phases: (1) Planning, (2) designing, (3) production, and (4) evaluation. In addition

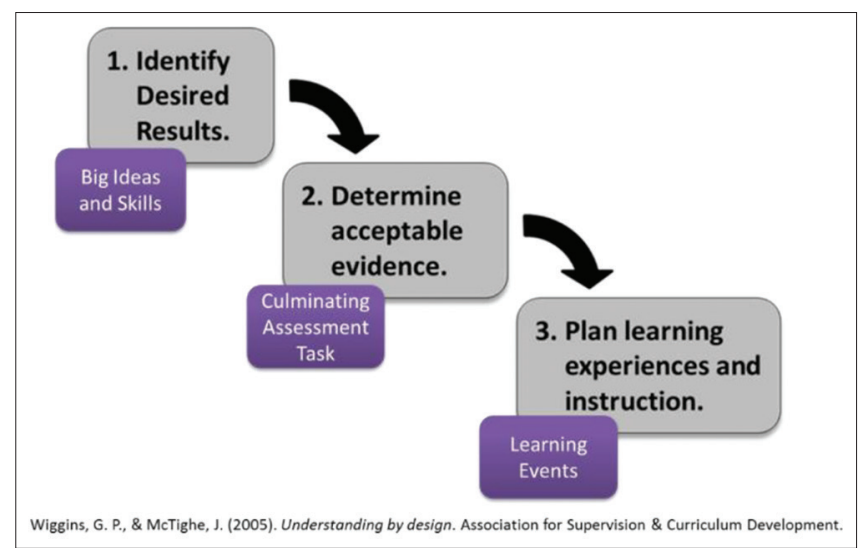

Figure 6: Representation of the backward design model

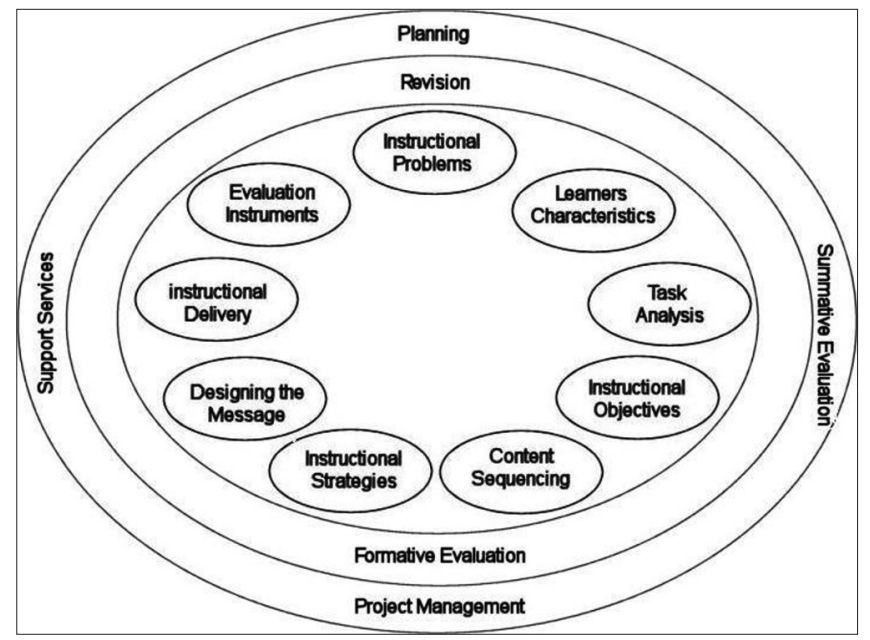

Figure 7: Representation of the Kemp Design Model. Image source: https://educationaltechnology.net/kemp-design-model/ to these phases, we have the formative evaluation process as well as the revision and continuous development, which result from the evaluation phase. Furthermore, marketing for to be developed product starts at early stages of development and continues until the end.

The planning, design, production, and evaluation phases consists of six, two, nine, and three steps, respectively (Figure 9a and b).

\section{PLAN PHASE}

Planning is crucial for the success of any project. If planning is performed inappropriately, i.e., if adequate time and effort are not expended during the planning phase, the quality of the resulting outcome would be subpar. This phase yields the steps required to achieve an effective, feasible, and worthwhile project. Figure 10 presents the steps of the planning phase for the ADIC model.

\section{Standards}

According to the ADIC model, planning starts with aligning the standards with the project to be developed. However, this alignment is more applicable to big projects, such as computerized curriculum, in which a connection to the Ministry of Education/Department of Education and specialty organization standards are necessary. The developer should start investigating the standards in the field of content and draw project outcomes based on these standards.

\section{Smart Outcomes}

Writing worthwhile measurable outcomes lead to a welldesigned and worthwhile project. The developer should initialize the project with the outcomes she/he plans to achieve. These outcomes should contain five features (SMART) that lead to the success of the project: (1) Specific addressing of the exact issue that must be achieved, (2) measurable and assessable, (3) achievable at a reasonable effort and time, (4) relevant to the field they address, and (5) time-bound to ensure that they can be achieved at a specified time.

\section{Theoretical Framework}

The selection of a framework before developing the project is highly important to ensure the success of the project, because it enables the developer to select appropriate learning strategies and activities. This framework could be a learning theory, an

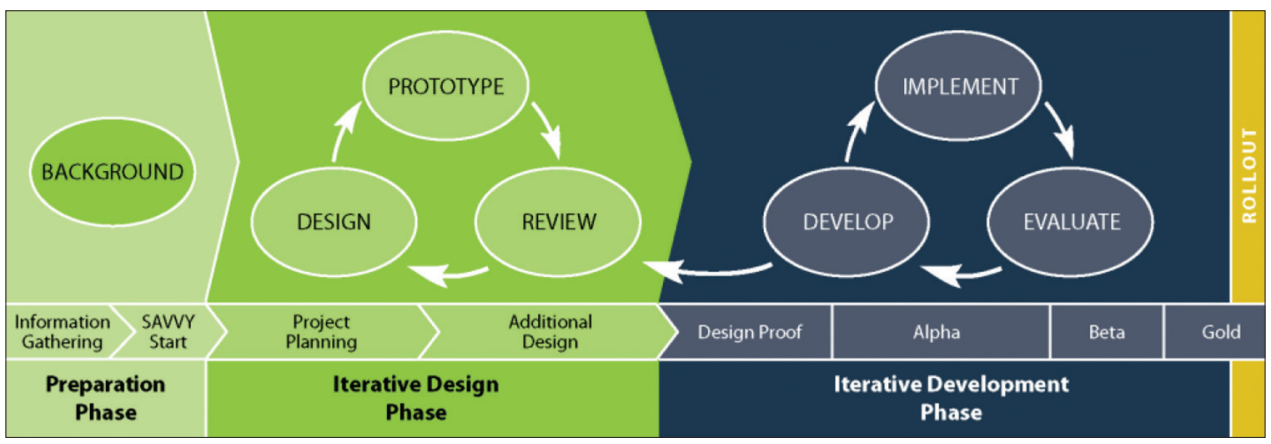

Figure 8: Representation of the successive approximation model. Image source: https://www.alleninteractions.com/sam-process 


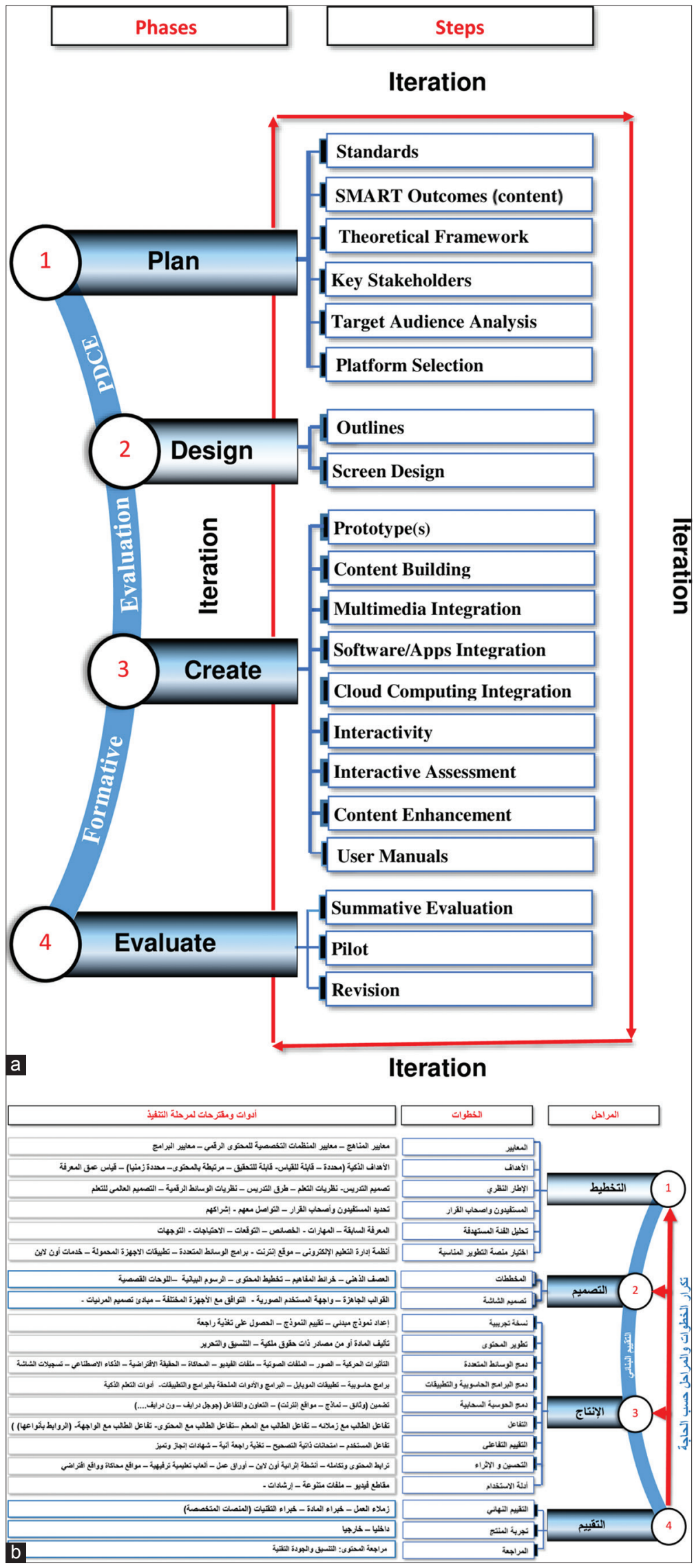

Figure 9: (a) Almekhlafi Digital Interactive Content Model. (b) Arabic translation of the Almekhlafi Digital Interactive Content model 
instructional design model, a teaching pedagogy, and/or a digital media theory.

\section{Key Stakeholders}

Forming a connection with key stakeholders is significantly crucial for the success of the project. As stakeholders include individuals, organizations, and institutions that can be affected by the outcomes of the project, it is important to cooperate with them and engage them in the process whenever possible. Furthermore, ensuring the satisfaction of stakeholders and their willingness to collaborate and participate in the project are essential. This makes it possible to proceed with the project with confidence and certainty.

\section{Target Audience Analysis}

The developer of any digital curriculum or content must analyze the target audience who will benefit from the product. The target audience could include students, teachers, trainees, or any other educators. Nevertheless, for all cases, knowing different characteristics of the target audience are considerably critical to ensure that the project is well received. Al Musawi (2011) pointed out that designers should look into learner's characteristic and needs. According to the researcher, designers need to do an analysis of their audience to know several characteristics such as demographic information, prior knowledge of the topic, and anxiety level. In addition, designers need to identify the ethical issues involved in the delivery processes such as equal opportunity, cultural diversity, and accessibility.

\section{Platform Selection}

The final step in this phase is selecting the platform that will be used to develop the interactive content. This platform could be a multimedia authoring software, mobile application, eLearning management system, or internet services.

\section{DESIGN PHASE}

The second phase in this model is the design phase. After completing all steps of the planning phase, we initiate the design phase, which consists of three steps (Figure 11): Outlining, screen design, and user manuals.

\section{Outlines}

The first step involves preparing an outline of the project, starting with brainstorming, which helps in generating ideas that enrich content. This is followed by concept mapping, content outline, flowcharting, and finally ending with storyboards.

\section{Screen Design}

The second step in the design phase is the screen design. In this step, the developer must consider a number of issues related to screen design, such as compatibility of the developed product with different devices. In addition, a navigation system should be designed to make it easier to use and navigate through the product. The application of visual design principles should be considered at this step. Al Musawi (2011) suggested that designers should make sure of the usability of interface design to facilitate learner's interactivity through the user interface. Designers should make sure the interface can support and ease navigation during the learning process.

\section{CREATE PHASE}

The production phase consists of nine steps. However, it should be noted that these steps do not necessarily have to be implemented in order (Figure 12).

\section{Prototype(s)}

The first step is to build a sample of the project and obtain feedback from users. If the received feedback for the prototype is positive, the remainder of the project will continue with the same design. If the users noted observations in their feedback, the project should be revised accordingly.

\section{Content Building}

The developer needs to add the content either himself/herself or by obtaining it from different sources, simultaneously retaining the copyright property. Once the content is added to

\begin{tabular}{|l||l|}
\hline \multicolumn{1}{|c|}{ Steps } & \multicolumn{1}{|c|}{ Implementation Tools and Suggestions } \\
\hline Standards & Curriculum Standards - Specialty Organizations Standards (digital Content) - Program(s) - \\
\hline SMART Outcomes (content) & SMART (Specific - Measurable - Achievable - Relevant - Time-bound) - Depth of Knowledge - \\
\hline \hline Theoretical Framework & Instructional Design - Learning Theories - Pedagogical Apparatus - Digital Media Theories - UDL - \\
\hline Key Stakeholders & Identify - Connect - Engage \\
\hline Target Audience Analysis & Knowledge - Skills - attitudes - Characteristics - Expectations - Needs - \\
\hline Platform Selection & eLMS - Website(s) - Multimedia Authoring Software - Mobile App(s) - Online Services - ? \\
\hline
\end{tabular}

Figure 10: Almekhlafi Digital Interactive Content plan phase

\begin{tabular}{|l|l|}
\hline Step & \multicolumn{1}{|c|}{ Implementation Tools and Suggestions } \\
\hline Outlines & Brainstorming - Conceptual Maps - Content Outline(s) - Flowchart(s) / Infographics - Storyboards - \\
\hline Screen Design & Templates - GUI - Compatibility (Mobile - Desktop - Interactive Whiteboards) - Navigation - VD Principles - \\
\hline \hline
\end{tabular}

Figure 11: Almekhlafi Digital Interactive Content design phase 
the project, the work should focus on editing and formatting, and the design should be considered.

\section{Multimedia Integration}

Multimedia is one of the key elements for creating any interactive digital content, regardless of its intended use and context. Thus, once the content is developed, the developer should start integrating multimedia elements into the project. Any integrated multimedia element (such as animation, graphics, videos, and simulation) should be feasible and contribute to the achievement of the project outcomes.

\section{Software and App Integration}

Similar to cloud computing, the integration of different types of software, apps, plug-ins, and widgets will definitely enhance the project and make it more interactive and engaging. Some of the software and apps can imbue life to the project and enhance its content; they can help the audience be submerged into the content and highly motivate them into learning the content.

\section{Cloud computing Integration}

The integration of cloud computing services in digital interactive content is significantly important to make the project interactive, appealing to the audience, and contentrich. Cloud computing services could include the integration of various files such as pdf files, images, videos, handouts, quizzes, and online collaboration activities.

\section{Interactivity}

As the content is expected to attract and engage the target audience, a major emphasis should be given to interaction. This interaction should cover all or some of the well-known four types of interaction: Student-student interaction, studentinstructor interaction, student-interface interaction, and student-content interaction. There are many different strategies and techniques that could lead to effective interaction, such as the use of hyperlinks, hotspots hyperlinks, and navigation menus and submenus.

\section{Interactive Assessment}

Assessment is a considerably important component of any educational content. As the goal is to create interactive content, the assessment must also be interactive. In addition, the assessment should include simultaneous feedback to the user. The developer can achieve this type of assessment using different techniques such as test makers, quiz-creator applications, and internet services.

\section{Enhancement and Enrichment}

The final step in the production phase is to enrich the product enhancement. The developer should enhance the project using online handouts, games, virtual reality, and simulations sites.

\section{User Manuals}

This step is significantly important for the success of any product based on the model. Documentation and user manuals are necessary; these manuals could take different forms such as videos, help files, and tips and tricks.

\section{EVALUATE PHASE}

The final phase in the model is the evaluation phase, which consists three steps, as shown in Figure 13.

\section{Summative Evaluation}

Once the digital content is developed, a summative evaluation for the project must be conducted. This evaluation could involve presenting the project to colleagues and requesting them to review it. Similarly, the project should be evaluated by content and technology experts.

\begin{tabular}{|l|l|}
\hline \multicolumn{1}{|l|}{ Implep } & Implementation Tools and Suggestions \\
\hline Prototype(s) & Authored and/or Copyrighted - Open educational resources (OER) - Text formatting and editing - \\
\hline Content Building & Animation - Graphics - Audio - Videos - Flash - Screen recording - Games - Simulation - VR- AR- AI - \\
\hline Multimedia Integration & Computer Software - Mobile Apps - Add-ons/Add-ins/Plugins/Extensions - Widgets - Smart Learning tools - \\
\hline Software/Apps Integration & Embedding (Docs - Forms - Sites) - Collaboration and Interaction (e.g., Google Drive - OneDrive ...) - \\
\hline Cloud Computing Integration & Student-Student/Instructor/Content/Interface Interaction - Hyperlinks (e.g., hotspots) - \\
\hline Interactivity & User input - Auto graded Quizzes - Simultaneous Feedback - Achievement certificates - \\
\hline Interactive Assessment & Coherence and integrity - Online Activities - Handouts - Games, Simulation, VR, and AR websites - \\
\hline Content Enhancement & Tutorials - Videos - FAQs - Tips and Tricks - \\
\hline User Manuals
\end{tabular}

Figure 12: Almekhlafi Digital Interactive Content create phase

\begin{tabular}{|l|l|}
\hline Step & Implementation Tools and Suggestions \\
\hline Summative Evaluation & Colleagues - Content Experts - Technology Experts (Specialized Platforms) - \\
\hline Pilot & Internally - Externally \\
\hline \hline Revision & Content Revision - Technical and Format Revision; Glitches and Mistakes, Updates - \\
\hline
\end{tabular}

Figure 13: Almekhlafi Digital Interactive Content evaluate phase 


\section{Pilot}

Once the summative evaluation is completed, the project must be piloted with a sample of users similar to the target audience. This could be conducted internally and externally, and the feedback from the users should be collected.

\section{Revision}

The project should be revised based on the feedback received from the summative evaluation and pilot. The following three issues should be revised as needed: Content, technical features, and format.

\section{METHODS}

\section{Participants}

Among the participants of the implementation of the ADIC model, 28 university faculty members were involved in the piloting of the model, and 81 university students were involved in the application and validation of the model. The university faculty members developed an interactive presentation following the ADIC model during a 3-day workshop, whereas the students developed two projects, each within 2 months, during the 2018 fall semester.

\section{VALIDATION AND EVALUATION}

\section{ADIC Model Content Validity}

Initially, the ADIC model was developed in three main phases, each consisting of numerous steps: Planning and design, production and refinement, and evaluation and revision. To content-validate the model, it was sent to more than 50 experts from different specializations including educational technology, general education, curriculum, instructional design, engineering, computer science, humanities, and IT. The experts included schoolteachers, university faculty members, technology experts, and k-12 educators from different countries such as the USA, Britain, China, Japan, Yemen, United Arab Emirates, Saudi Arabia, Egypt, Jordan, Oman, and Sudan.

In addition, the model was presented to 31 university faculty members during a 1-h workshop. Participants were requested to provide their feedback on the model through a survey.

Based on the feedback received from the experts and workshop attendees, the model was revised, and few alterations, such as changes in the number of phases and order of steps, were implemented. In addition, few steps were deleted, whereas others were added. Figure 14 presents the initially developed ADIC model.

\section{Model Reliability}

For reliability, the model was applied in two contexts: With university faculty members and with pre-service teachers (students studying at the College of Education, United Arab Emirates University [UAEU]).

\section{Faculty Members}

The first use and application of the model were conducted by 28 local university faculty members as part of their professional development activities. During a 3-day workshop, participants were trained to design and create a digital interactive lecture based on the ADIC model. Once the participants completed the project, they were requested to fill in a questionnaire. The data collected were used as a pilot for the model and as validation for the survey.

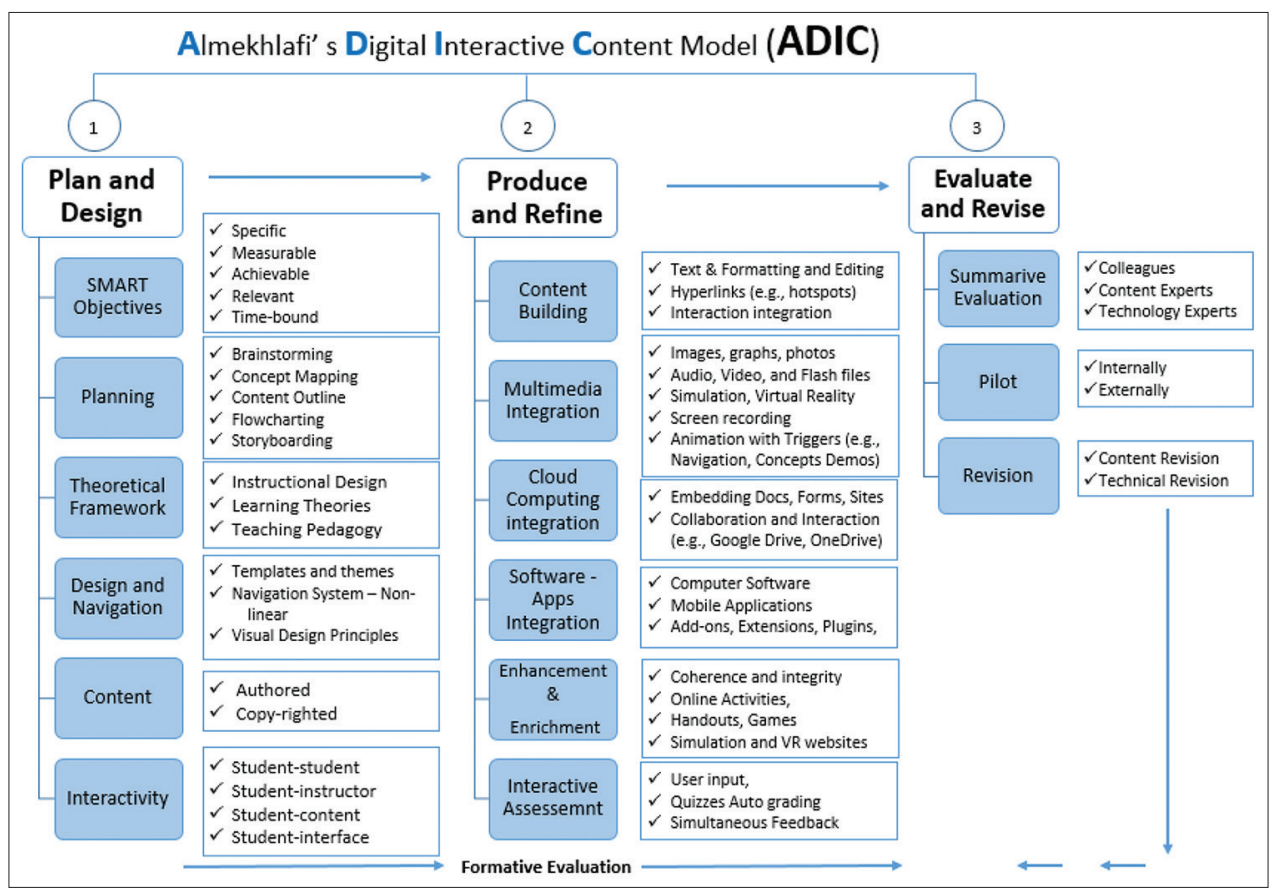

Figure 14: An older version of the Almekhlafi Digital Interactive Content model 


\section{Students}

As part of the model implementation and evaluation, students from a technology course developed two interactive digital content projects based on the model. The students spent an entire semester designing and creating these two projects. The first project was designed during the first half of the 2018 fall semester, and the second project was developed and created during the second half of the semester.

Two instruments were used to evaluate the utility and feasibility of the ADIC model: An implementation checklist and perception survey. After completing the projects, students were requested to fill in the survey and checklists.

\section{INSTRUMENT VALIDITY AND RELIABILITY}

Two instruments were developed and used for evaluating the ADIC model:

\section{Questionnaire}

A questionnaire based on the 5-point Likert scale was prepared to investigate the participants' perceptions of the utility and feasibility of the ADIC model. The survey consisted of 20 items, with ratings of (1) strongly disagree, (2) disagree, (3) undecided, (4) agree, and (5) strongly agree. A panel of university professors from different specializations, including technology, curriculum, statistics, and IT, validated the survey.

Based on the feedback received from the panel of experts, few changes were implemented, including rephrasing some of the questionnaire items. Once the questionnaire was completed, it was piloted with 28 university faculty members at a local university. After conducting a workshop on the model, participants were requested to fill in the survey. Cronbach's alpha was 0.977 , which indicates a high reliability of the questionnaire.

\section{Checklist}

A checklist was created based on the validated questionnaire. However, instead of the 5-point Likert scale, three levels of measurements were used: Not applicable, yes, and no. The checklist aimed at checking the implementation of the students' projects developed based on the ADIC model for triangulating data collected through the questionnaire. Similar to the survey, the checklist was validated by several university professors.

\section{MODEL IMPLEMENTATION}

As previously mentioned, the model was implemented to be used by pre-service teachers studying at the college of education. The students implemented the model while developing two projects during a technology course.

\section{Project 1: Designing and Creating Interactive Digital Content}

In this project, students were expected to design and create an interactive digital content project covering at least a lesson from the k-12 school curriculum in their area of specialization. In this lesson, the student must integrate a number of technologies that can be used to teach this lesson. The student is required to create the project using any multimedia authoring software, such as MS PowerPoint, iBooks Author, or any software the student feels comfortable with. The ADIC model was used as the framework for planning, producing, and evaluating the project. Figure 15 shows a screenshot of one of the created projects as a sample; the student's consent was obtained to use these screen shots for academic purposes.

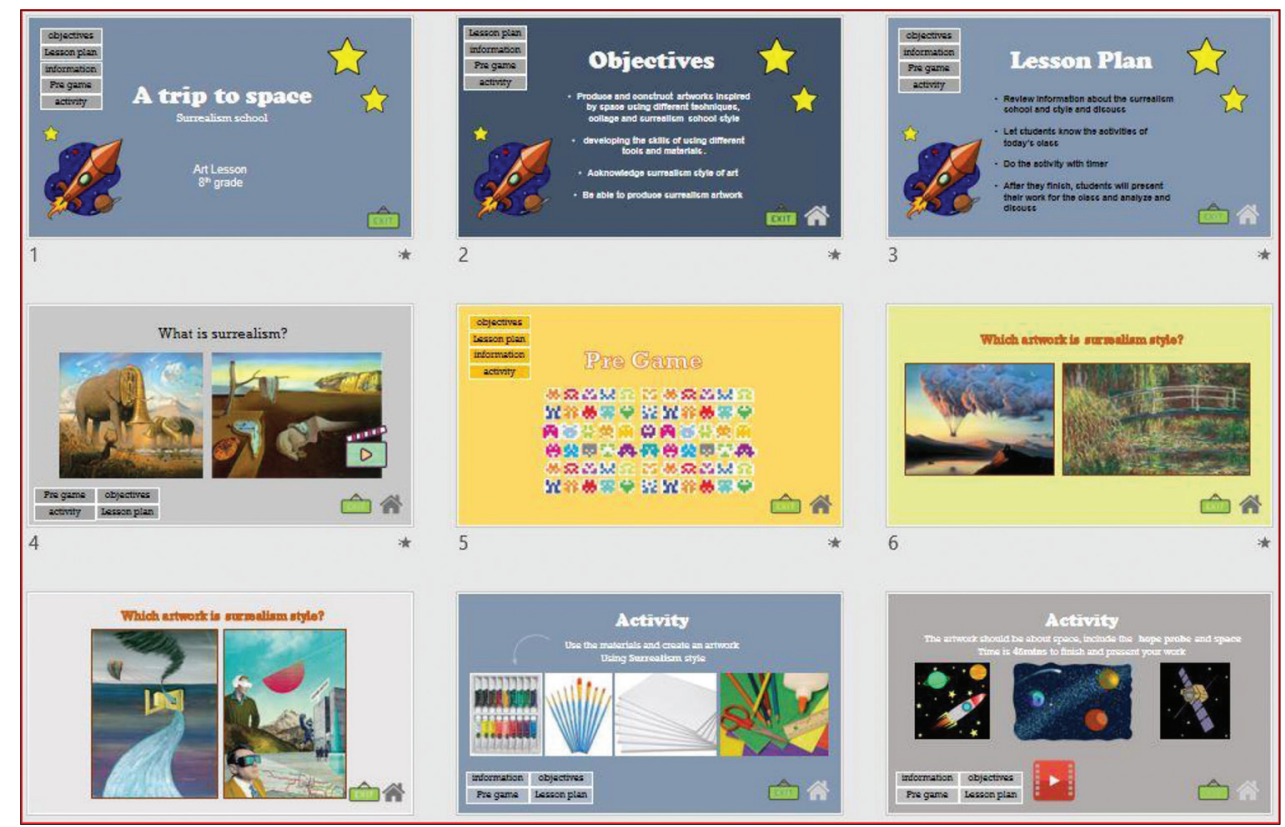

Figure 15: Screenshot of designing and creating the interactive digital content project 


\section{Project 2: Designing and Creating an Electronic Portfolio} For this task, students were expected to create an electronic portfolio organized around the nine elements of the UAEU College of Education, mission, vision, and conceptual framework.

The portfolio was developed as a website in the form of a collection of the works previously completed in this class and/ or other classes attended by the student. This portfolio will be the starting point for the required portfolio that students must submit to the college at different stages in the program, including the capstone and field experience courses. Students can use any web-authoring software, apps, cloud computing services, or a combination of some of these programs or applications to create this portfolio. Moreover, similar to Project 1, the ADIC model is used as the framework for this project. Figure 16 shows a screenshot of the sample of one of the created e-Portfolios.

\section{RESULTS AND DISCUSSION}

For the first question "How do students perceive the utility of the ADIC model for designing and developing interactive digital content?," the mean scores of the participants ranged from 3.95 to 4.33 on a 5-point Likert score. Participants had highly positive perceptions toward all five phases of the model. For the planning phase, the mean scores of the participants ranged from 4.0 to 4.3. Similarly, their perceptions for the design phase ranged from 4.2 to 4.3. Furthermore, the main scores of the production phase ranged from 4.0 to 4.3. Similar to this phase, the main scores of the participants for the last phase of the model ranged from 4.1 to 4.3. As shown in Table 1, all items received high positive scores, indicating high selfperceptions of model utility.

For the second question "To what extent do participants implement the ADIC model for creating digital interactive content?," the results showed that students found the implementation of the model considerably beneficial for their projects (Table 2). It is worth mentioning that the students' projects were not large-scale projects such as computerized curriculum or training modules. This implies that few of the model's steps, such as standards and stakeholders, will not be required in the planning phase. Similarly, some details within the steps are not essential for the effectiveness of the students' projects.

The results show that the participants' implementation of the first phase of the model was evident for the items related to their projects. The model implementation for the SMART outcomes was $100 \%$ and $87 \%$ for Project 1 and 2 , respectively. The analysis of the target audience achieved $92 \%$ and $74 \%$ for Project 1 and 2, respectively. Similarly, platform selection achieved $92.1 \%$ and $72.9 \%$ for Projects 1 and 2, respectively.

The results of Phase 2 revealed percentages of $91 \%$ and $83.9 \%$ for outlining and 87.8 and 87.1 for screen design for Project

\begin{tabular}{|c|c|c|}
\hline \multirow[t]{2}{*}{ ADIC model steps } & \multicolumn{2}{|c|}{ Students } \\
\hline & Mean & SD \\
\hline \multicolumn{3}{|l|}{ Planning phase } \\
\hline The model helped me connect my project to the standards & 4.3 & 0.7 \\
\hline The model helped me create SMART objectives for the content I developed & 4.3 & 0.7 \\
\hline The model helped me identify key stakeholders for my project & 4.0 & 0.7 \\
\hline The model helped me analyze the target audience for my project & 4.3 & 0.7 \\
\hline The model helped me think and use the right theoretical framework for my project & 4.1 & 0.7 \\
\hline The model helped me select the right platform for my project & 4.11 & 0.7 \\
\hline \multicolumn{3}{|l|}{ Design phase } \\
\hline The model helped me plan well for the project I developed using planning tools such as flowcharts & 4.3 & 0.7 \\
\hline The model helped me create a nice screen for my project & 4.2 & 0.8 \\
\hline \multicolumn{3}{|l|}{ Create phase } \\
\hline The model helped me prepare a prototype for my project & 4.0 & 0.8 \\
\hline The model helped me build the content for my project & 4.2 & 0.7 \\
\hline The model helped me integrate different multimedia elements into my project & 4.3 & 0.6 \\
\hline The model helped me plan for interactivity I used in my project & 4.1 & 0.7 \\
\hline The model helped me integrate different cloud computing services into my project & 4.0 & 0.8 \\
\hline The model helped me integrate a number of computer software into my project & 4.2 & 0.7 \\
\hline The model helped me create interactive assessment into my project & 4.3 & 0.7 \\
\hline The model helped me enhance my project with a number of enrichment resources & 4.2 & 0.7 \\
\hline \multicolumn{3}{|l|}{ Evaluation phase } \\
\hline The model helped me do the summative evaluation & 4.3 & 0.7 \\
\hline The model helped me pilot the project & 4.1 & 0.7 \\
\hline The model helped me revise my project & 4.2 & 0.6 \\
\hline
\end{tabular}




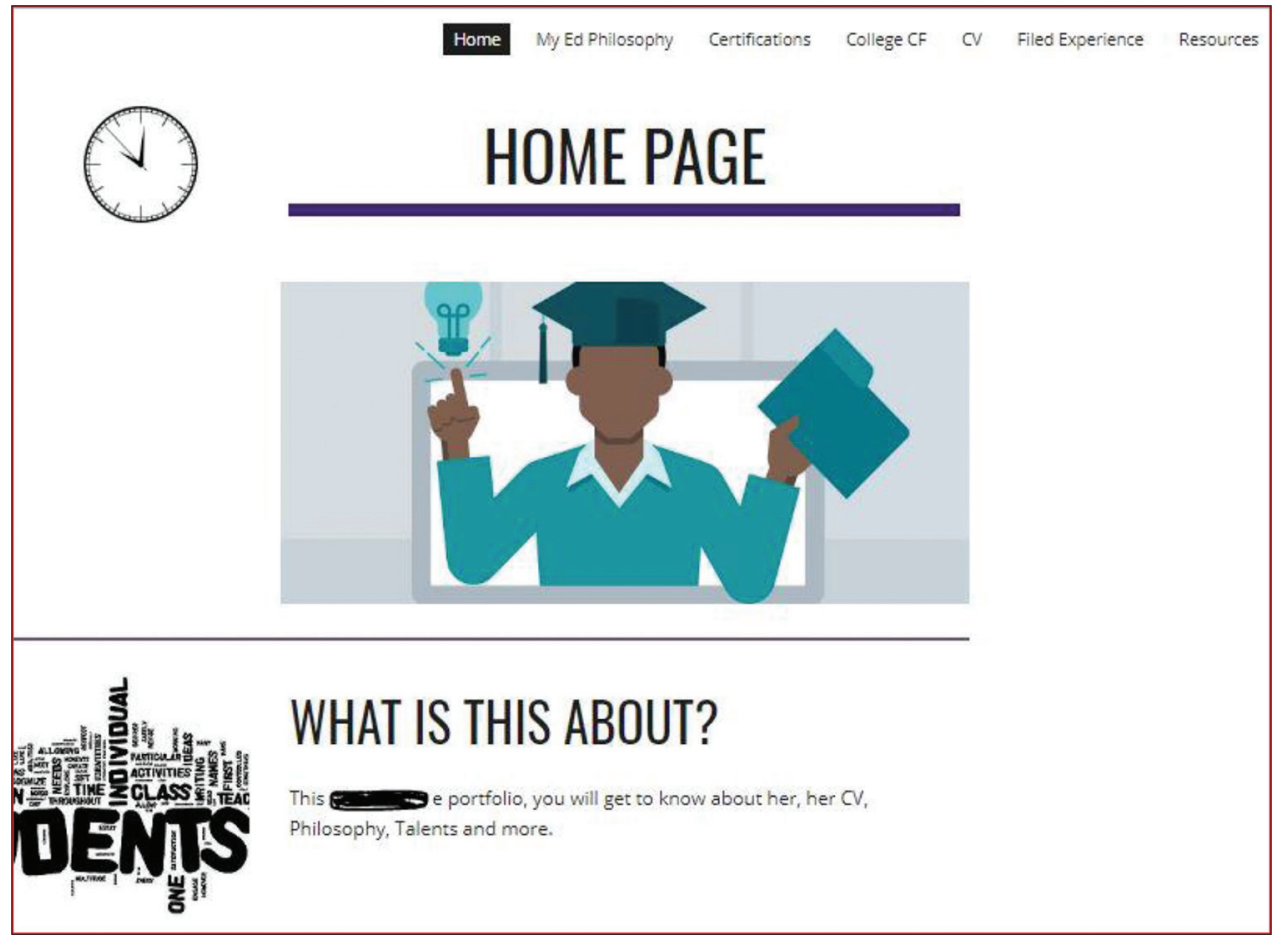

Figure 16: Screenshot of the first screen of the electronic portfolio project

\begin{tabular}{|c|c|c|c|c|c|c|}
\hline \multirow[t]{3}{*}{ ADIC model steps } & \multicolumn{6}{|c|}{$\%$} \\
\hline & \multicolumn{3}{|c|}{ Project 1} & \multicolumn{3}{|c|}{ Project 2} \\
\hline & NA & No & Yes & NA & No & Yes \\
\hline \multicolumn{7}{|l|}{ Planning phase } \\
\hline Standards & 70.0 & 2.2 & 27.8 & 83.9 & 1.6 & 14.5 \\
\hline SMART outcomes & 0.00 & 0.0 & 100 & 9.7 & 3.2 & 87.1 \\
\hline Key stakeholders & 64.4 & 3.3 & 32.2 & 87.1 & 4.8 & 8.1 \\
\hline Target audience analysis & 7.8 & 0.0 & 92.2 & 16.1 & 9.7 & 74.2 \\
\hline Theoretical framework & 2.2 & 4.4 & 93.3 & 85.5 & 1.6 & 12.9 \\
\hline Platform selection & 0.0 & 8.9 & 92.1 & 14.5 & 12.9 & 72.6 \\
\hline \multicolumn{7}{|l|}{ Design phase } \\
\hline Outlines & 7.8 & 1.1 & 91.1 & 11.3 & 4.8 & 83.9 \\
\hline Screen design & 3.3 & 8.9 & 87.8 & 4.8 & 8.1 & 87.1 \\
\hline \multicolumn{7}{|l|}{ Create phase } \\
\hline Prototype preparation & 34.4 & 15.6 & 50.0 & 11.3 & 14.5 & 74.2 \\
\hline Content building & 14.4 & 7.8 & 77.8 & 11.3 & 16.1 & 72.6 \\
\hline Multimedia integration & 2.2 & & 97.8 & 6.5 & 9.7 & 83.9 \\
\hline Interactivity & 3.3 & 1.1 & 95.5 & 4.8 & 4.8 & 88.7 \\
\hline Cloud computing integration & 7.8 & 22.2 & 70.0 & 8.1 & 24.2 & 67.7 \\
\hline Software/apps integration & 5.6 & 13.3 & 81.1 & 8.1 & 17.7 & 74.2 \\
\hline Interactive assessment & 12.2 & 7.8 & 80.0 & 74.2 & 3.2 & 22.6 \\
\hline Enhancement and enrichment & 8.9 & 1.1 & 90.0 & 14.5 & 22.6 & 62.9 \\
\hline \multicolumn{7}{|l|}{ Evaluation phase } \\
\hline Summative evaluation & 27.8 & 16.7 & 55.6 & 79.0 & 6.5 & 14.5 \\
\hline Pilot & 56.7 & 10.0 & 33.4 & 19.4 & 29.0 & 51.6 \\
\hline Revision & 14.4 & 8.9 & 76.7 & 6.5 & 24.2 & 69.4 \\
\hline
\end{tabular}

Table 3: Participants' subjective norm (intent to recommend the model to others)

\begin{tabular}{lccc}
\hline Group & $\mathbf{n}$ & Mean & SD \\
\hline Students & 81 & 7.5 & 1.5 \\
Faculty members & 28 & 7.8 & 2.6 \\
\hline \multicolumn{2}{l}{ The promoter scale ranged from 0 to 10} & &
\end{tabular}

1 and 2, respectively. Thus, the implementation of this phase of the model was significantly effective for the two projects. Moreover, the implementation a majority of steps of Phase 3 was evident.

For the third question "To what extent do participants intend to use or recommend the ADIC model to colleagues or others for the design and development of digital content materials?," both students and faculty members indicated that they intended to use the model or recommend it to their colleagues. The mean scores of students and faculty members were 7.5. and 7.8 , respectively, based on the net promoter score that ranged from 0 (Not at all likely) to 10 (extremely likely), as shown in Table 3. This indicates that teachers and students liked the model and found it useful for developing and designing digital interactive content. Thus, they recommended it to others.

\section{CONCLUSION}

The study results showed that the proposed ADIC model is an effective tool for designing and creating digital interactive content. This was evident from the results of the two projects 
developed by students employing the model as the framework. The students assigned high scores to the utility of the model in helping them systematically develop their projects. Their perceptions toward the use of the model were positive, and they were likely to recommend the model to other users in the future. Similar to students, faculty members had a highly positive attitude toward the model and also intended to recommend it to their colleagues.

Based on these results, k-12 schools, higher education institutions, and other educational entities may benefit from this model, for the development of any instructional digital material. Curriculum developers, instructional designers, teachers, and trainers will definitely benefit in one way or another from this generic flexible model.

However, to generalize the model across various fields, further detailed investigations of the model are required. Research should be conducted on the implementation of the model under different contexts in k-12 schools and higher education institutions. In addition, additional time should be allocated for the implementation of the model, to improve the validity and accuracy of the results. Similarly, the model should be implemented with respect to large-scale projects such as computerized curriculum, materials for online and blended learning courses, and training modules.

\section{REFERENCES}

Akbulut, Y. (2007). Implications of two well-known models for instructional designers in distance education: Dick-Carey versus Morrison-RossKemp. Turkish Online Journal of Distance Education, 8(2), 62-68.

Al Musawi, A.S. (2011). Blended learning. Journal of Turkish Science Education, 8(2), 3-8.

Branch, R.M. (2009). Instructional Design: The ADDIE Approach. Berlin, Germany: Springer Science+Business Media.

Chang, S.L. (2006). The systematic design of instruction. Educational
Technology, Research and Development, 54(4), 417-420.

Crowe, S. (2019). Iterative eLearning Development with SAM. Available from: https://www.alleninteractions.com/sam-process

Dick, W. (1996). The Dick and Carey model: Will it survive the decade? Educational Technology Research and Development, 44(3), 55-63.

Dick, W., \& Carey, L. (1996). The Systematic Design of Instruction. $4^{\text {th }}$ ed. New York: Harper Collins College Publishers.

Dick, W., \& Reiser, R.A. (1989). Planning Effective Instruction. New Jersey, United States: Prentice Hall.

Dick, W., Carey, L., \& Carey, J. (2015). The Systematic Design of Instruction. London, United Kingdom: Pearson.

Dick, W., Carey, L., \& Carey, J.O. (2001). The Systematic Design of Instruction. New York: Longman.

Francom, G., \& Reeves, T. (2010). A Significant Contributor to the Field of Educational Technology. Englewood Cliffs, NJ: Educational Technology Publications, Inc. $7^{\text {th }}$ ed. Available from: http://www.media. wix.com/ugd/8596b6_52421b72d50c08350906269932a6f36c.pdf.

Gustafson, K.L., \& Branch, R.M. (2002). What is instructional design? In: Reiser, R.A., \& Dempsey, J.A., (Eds.), Trends and Issues in Instructional Design and Technology. United States: Merrill/Prentice-Hall. pp. 16-25.

Heinich, R., Molenda, M., Russell, J.D., \& Smaldino, S.E. (1999). ASSURE Model. Available from: http://www.ed205.net/assure_model.html.

Kurt, S. (2016). Kemp Design Model. Available from: https://www. educationaltechnology.net/kemp-design-model.

Merrill, D. (2002). First principles of instruction. Educational Technology Research and Development, 50(3), 43-59.

Morrison, G.R. (2010). Designing Effective Instruction. $6^{\text {th }}$ ed. United States: John Wiley \& Sons.

Rothwell, W.J., Benscoter, B., King, M., \& King, S.S. (2015). Mastering the Instructional Design Process: A Systematic Approach. $5^{\text {th }} \mathrm{ed}$. United States: John Wiley \& Sons.

Van Merriënboer, J.J.G. (1997). Training Complex Cognitive Skills: A Four-component Instructional Design Model for Technical Training. Englewood Cliffs, NJ: Educational Technology Publications.

Van Merriënboer, J.J., Clark, R.E., \& de Croock, M. (2002) Blueprints for complex learning: The 4C/ID-model. Educational Technology Research and Development, 50(2), 39-64.

Wiggins, G., \& McTighe, J. (1998). Understanding by Design. Virginia, United States: ASCD.

Wiggins, G., \& McTighe, J. (2005). Understanding by Design. Virginia, United States: ASCD. 